DOI: https://doi.org/10.30749/2594-8261.v4n2p409-427

\title{
PRESENÇA NEGRA NO ESTADO DO AMAZONAS: A CONTRIBUIÇÃO DOS ARQUIVOS DO TJAM
}

\section{BLACK PRESENCE IN THE AMAZON STATE: THE CONTRIBUTION OF TJAM ARCHIVES}

\section{Juarez Clementino da Silva Junior*}

Resumo: A presença negra na Amazônia e notadamente no Amazonas tem uma histórica negação ou minoração. Parte por ter pertencido a outra colônia portuguesa nas Américas, o Grão-Pará e Maranhão, integrado ao estado do Brasil após a independência desse último e que pelas características da região teve exploração econômica diferente em relação a outras regiões, com uso bem mais modesto de mão de obra escravizada negroafricana. Na segunda metade do século XIX havia uma não reduzida parcela de negros livres e libertos na população, além de uma parcela menor de ainda escravizados. Outra parte da negação, vem da modernização trazida pelo fausto da borracha, a cidade de Manaus aspirava ser uma "Paris dos Trópicos", essa aspiração cosmopolita da "Belle Epoque" se alinhava a outra, higienista, em que as figuras do negro e do indígena deveriam ser se não fisicamente eliminadas, ao menos ocultadas. O que acabou se tornando crença popular de não presença negra até muito recentemente. Nos últimos anos a academia se voltou à desconstrução dessa negação, através de várias pesquisas de pós-graduação, sobretudo em História. Parte das pesquisas tem utilizado o acervo histórico do arquivo do Tribunal de Justiça do Amazonas. Aliás o acervo foi premiado em 2018 com o selo "Memórias do mundo" da UNESCO, pelo conjunto documental "Africanos livres na Justiça amazonense do Séc. XIX", sendo o primeiro e único acervo do estado a possuir tal distinção.

Palavras chave: Presença. Negra. Amazonas. Justiça. Arquivos.

Abstract: The black presence in the Amazon has a historic denial or diminution. It happened because it belonged to another portuguese colony in the Americas, only integrated with the state of Brazil after the independence of this and also due to the characteristics of the region had different economic exploitation in relation to other regions, with much more modest use of black African enslaved work. In the second half of the nineteenth century, a portion of free and freed blacks was not reduced in the population, in addition to a drop in still enslaved people. Part of the denial, comes from the modernization brought about by the rubber boom, the city of Manaus aspired to be a "Paris of the Tropics", that cosmopolitan aspiration of the "Belle Epoque" was aligned to another, hygienist, in which the figures of the black and the indigenous peoples should be, if not physically eliminated, at least hidden. What turned out to be a popular belief of non-black presence until very recently. In recent years, the academy has turned to the deconstruction of this denial, through various postgraduate research, especially in history. Some of that research has used the historical collection from the archives of the Amazonas Court of Justice. In fact, the collection was awarded in 2018

\footnotetext{
* Mestre em História pela Universidade Federal do Amazonas (UFAM). Especialização em Educação a Distância pela Universidade Católica de Brasília (UCB). Graduado em Tecnologia em Processamento de Dados pela Universidade de Taubaté (UNITAU). E-mail: juarez_silva@hotmail.com.
} 
with the UNESCO seal "Memories of the world", for the documentary set "Free Africans in the 19th century Amazonian Justice", being the first and only state collection to have such distinction.

Keywords: Presence. Black. Amazon. Justice. Archives. 


\section{INTRODUÇÃO}

O texto ora colocado visa no objetivo geral demonstrar sucintamente a utilidade dos arquivos judiciais em geral nas pesquisas que envolvem as relações raciais ao longo do tempo, já que sendo o racismo uma estrutura, é importante observá-lo na longa, média e curta duração temporal a fim de ter subsídios para desconstruí-lo, pois a problematização histórica social não se presta apenas para mera observação e registro do passado, mas também para refletir e alterar o possível e necessário no presente e futuro. No específico mostrar como tal tem sido realizado por meio dos arquivos do TJAM - Tribunal de Justiça do Estado do Amazonas e as suas potencialidades.

Entre as linhas propostas no presente dossiê são várias as que poderiam ser contempladas por tais potencialidades, a saber: Memória: Patrimônio Cultural imaterial; Memória e esquecimento: a importância dos Arquivos do Poder Judiciário; Arquivos judiciários e resgate da Memória; O Poder Judiciário no Império; Escravidão no Brasil e Poder Judiciário; Cidadania e Memória do Poder Judiciário; e em especial, Minorias e Memória do Poder Judiciário.

\subsection{Metodologia}

Expositiva, apresentando sequencialmente as seções, inicialmente tratando sucintamente da importância dos arquivos como fonte, apresentando o conceito e o campo de estudos de presença negra com referenciais. Na sequência o contexto em que se dá a pesquisa no acervo do TJAM, as potencialidades e o estado da pesquisa na temática utilizando o acervo, um uso institucional do acervo atestando a sua qualidade na temática e as conclusões.

\section{MARCO TEÓRICO}

\subsection{Processos judiciários como fontes}

Tendo o Poder Judiciário a missão de fazer cumprir a lei, dirimir os mais diversos conflitos sociais e controlar historicamente, mesmo que as vezes de forma 
indireta, muitos registros públicos, é natural que a sua documentação produzida seja grande fonte de pesquisa para diversas ciências, sobretudo as sociais, dai que o arquivo costuma receber pesquisadores de universidades locais, de outros estados ou mesmo de fora do país. Há também pesquisas que não são acadêmicas, mas para elaboração de livros por exemplo. A importância dos Arquivos Judiciais e dos processos judiciais como fonte de pesquisa hoje é notória, a valorização que o próprio Poder Judiciário vem dando à memória é outro indicativo. Como a questão já tem uma discussão ampla e bem elaborada e por economia textual, já que apesar de útil, não prejudica sobremaneira a apreensão do nosso objeto, não a detalharemos aqui, nos valendo do recurso do hipertexto, caso entenda o leitor um percurso necessário ou interessante. (KICH, 2010).

Já são vários os trabalhos acadêmicos realizados a partir de informações contidas no acervo do TJAM, alguns na temática presença negra e detalhados mais adiante, cuja potencialidade e importância é reconhecida pela comunidade acadêmica não apenas local, visto ter servido a vários pesquisadores de outros estados e países. O acervo do TJAM também recebeu reconhecimento ao receber em 2018 o selo "Memórias do mundo" (MoW-Brasil) outorgado pela UNESCO, para o conjunto documental "Africanos livres na Justiça amazonense do Séc. XIX", sendo o primeiro e único acervo do estado a possuir tal distinção.

\subsection{Presença Negra}

Os estudos de presença negra são relativamente recentes sob essa denominação, e partem de um novo paradigma epistemológico reivindicado por autores reconhecidos nas temáticas afro-brasileiras, a exemplo de Henrique Cunha Jr.:

A democracia prevê a representação de todos os grupos sociais em todas as
instâncias de decisão. No estágio atual do capitalismo, a pesquisa científica
e os grupos de pesquisadores constituem um grupo privilegiado de exercício
do poder, quer pela ação direta na participação nos órgãos de decisão do
Estado, quer pela ação indireta através da difusão dos conhecimentos que
justificam as ações dos poderes públicos. Os grupos sociais cujos membros
não fazem pesquisa ficam alijados dessas instâncias de poder. A ausência
de pesquisadores negros tem reflexo nas decisões dos círculos de poder.
Vide que temas como a educação e a saúde dos afrodescendentes só
passam para a pauta do Estado brasileiro depois que os movimentos negros,
com esforços próprios, formaram uma centena de especialistas e 
pesquisadores nessas áreas e produziram um número relevante de trabalhos científicos. [..]

[..] A formação dos pesquisadores negros passa por todos esses obstáculos ideológicos, políticos, preconceituosos, eurocêntricos, de dominações e até mesmo de inocências úteis vigentes nas instituições de pesquisa e nos órgãos de decisão sobre as políticas científicas. É fundamentalmente um problema político de concepção da sociedade e das relações sociais. Problema que a sociedade científica se nega a reconhecer como um problema, se negando a tratá-lo e colocá-lo na agenda das preocupações. O mesmo ocorre na esfera governamental, que de certa forma reflete o pensamento das instituições de pesquisa. (CUNHA JUNIOR, 2003, p. 2-3).

Conforme se pode depreender Cunha Junior observa que as temáticas ou campos de pesquisa precisavam ser pautados a partir da maior participação de pesquisadores negros em perspectivas menos eurocêntricas, o que influenciaria o fazer científico, o pensamento acadêmico e mesmo a agenda governamental. Passadas quase duas décadas e com as mudanças de mentalidade na academia, as políticas afirmativas que levaram mais negros e negras à universidade e consequentemente à pesquisa, se observa na academia $e$ instituições governamentais, não apenas o aumento da pesquisa nas temáticas negras, mas a própria alteração da episteme.

Nesse sentido epistêmico Nilma Lino Gomes apoiada em Boaventura Souza Santos, diz:

\begin{abstract}
Para Santos (2006, p. 154) "a ecologia dos saberes é um conjunto de epistemologias que partem da possibilidade da diversidade e da globalização contra-hegemônicas e pretendem contribuir para credibilizá-las e fortalecêlas". Ela se assenta em dois pressupostos: 1) Não há epistemologias neutras e as que reclamam sê-lo são as menos neutras; 2) a reflexão epistemológica deve incidir não nos conhecimentos em abstrato, mas nas práticas de conhecimento e seus impactos noutras práticas sociais. Quando falo de ecologia de saberes, entendo-a como ecologia de práticas de saberes (SANTOS, 2006, p. 154). Dessa forma, a ecologia dos saberes poderá nos ajudar a compreender a produção, a história, as tensões e os desafios vividos pela intelectualidade negra brasileira destacando o caráter inovador, contestador e a radicalidade política do conhecimento e das práticas por ela produzidos. (SANTOS, 2006, p. 154 apud GOMES, 2010, p. 493).
\end{abstract}

Essa alteração na ecologia de saberes já vinha na prática se desenhando havia alguns anos, quando passou a incluir de forma menos tímida, o negro não apenas como objeto, mas também sujeito da pesquisa temática, porém não apenas, também pesquisadores não-negros interessados na temática sob uma perspectiva de colonial. É a partir dai que os estudos de presença negra ganham destaque sob essa denominação. Aparentemente não houve uma preocupação generalizada em conceituar ou delimitar formalmente o campo de estudos, uma definição publicada é: 
A partir da configuração instalada nos 60 e 70 do século $X X$, foi possível avançar para novos campos e subcampos da pesquisa envolvendo a população negra, esses campos que permitiam visualizar e fornecer subsídios não apenas para a análise e conhecimento de peculiaridades mais recortadas, como por exemplo, territórios negros e "Quilombismo", "Saúde da População Negra", "Gênero e Raça", entre outros. O termo "Presença negra" já é percebido em publicações do final do XX, como no artigo de Luis Balkar Sá Peixoto Pinheiro, De mocambeiro a cabano: Notas sobre a presença negra na Amazônia na primeira metade do século XIX (1999). No início dos anos 2.000 aparece em diversos textos e recortes de presença, como no texto $A$ trajetória do negro na literatura brasileira, de (PROENÇA FILHO, 2004), ou no A representação do negro na política brasileira (SILVA, 2004). O estudo de "presença" pode então ser entendido em linhas gerais como todo aquele que visa demonstrar e explicar a existência de determinado elemento em um contexto, mesmo quando e onde tal presença não é tradicionalmente contestada, fazendo-se nesse caso o registro e o esclarecimento da mesma. Porém, sua maior utilidade e aplicação se dá nos contextos em que determinada presença é tradicionalmente negada ou "invisibilizada". Portanto, seriam então os estudos de presença negra, aqueles executados por meio de abordagens diversas, isoladamente, ou seja, de forma histórica, cultural, demográfica/estatística, sociológica e antropológica ou, ainda, de forma interdisciplinarmente combinada. (SILVA JUNIOR, 2019, p. 6768 , grifo nosso).

Hoje uma busca com a chave "presença negra" no Google Scholar, máquina de busca web dedicada a trabalhos acadêmicos, retorna cerca de 4,5 mil resultados, ou seja, publicações que se abrigam sob o guarda-chuvas e títulos que contém o termo presença negra. Muito embora haja escasso uso anterior, é de 2011 a obra que inaugura a fase consciente e consistente de tais estudos sob a denominação no Amazonas, trata-se do livro "O FIM DO SILÊNCIO: presença negra na Amazônia", coletânea com textos de 13 autores, organizado pela Professora Doutora Patricia Melo Sampaio, estudiosa da temática, incentivadora e orientadora de toda uma geração amazonense de pesquisadores especialmente dedicados ao tema, que sobre o mesmo afirmou:

[..] tema tido como fundamental nos mais diferentes campos acadêmicos: economia, sociologia, antropologia, direito, além da história, obviamente. Contudo em se tratando de Amazônia e, mais particularmente, do Amazonas, estamos diante de um tema muito pouco frequentado pelos estudiosos. Um silêncio persistente que insiste em apagar memórias, histórias e trajetórias de populações muito diversificadas que fizeram desta região seu espaço de luta e sobrevivência. Esta é uma dívida de muitas gerações que ainda reclama sua paga. (SAMPAIO, 2011, p. 8). 
Figura 1 - Capa do livro.

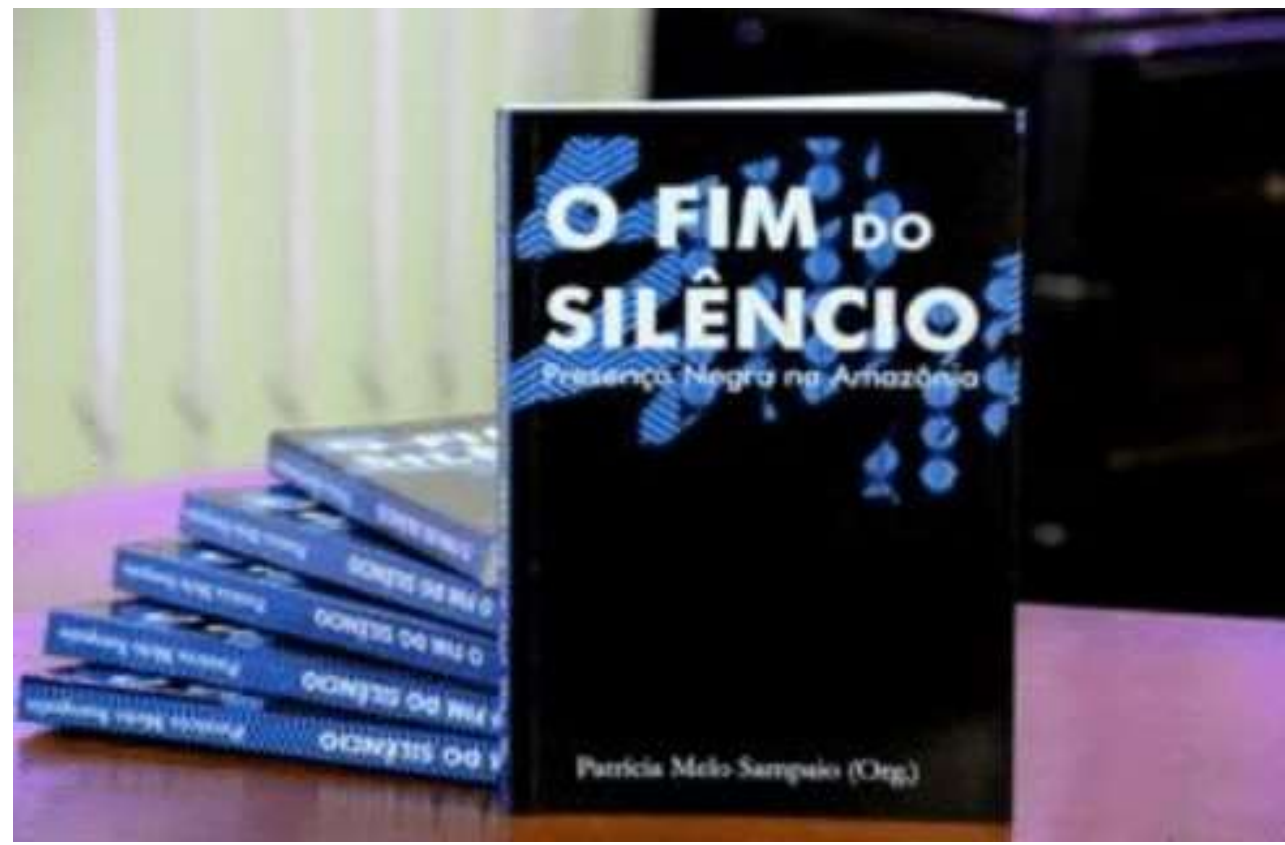

Fonte: Autor (2020).

A coletânea traz os autores Ygor Olinto Rocha Cavalcante, tratando de escravidão, liberdades e fugas no Amazonas Imperial, Provino Pozza Neto, com alforrias, Luís Carlos Bonates, sobre história da Capoeira no Amazonas, Emmanuel de Almeida Farias Júnior, sobtre quilombolas do baixo Amazonas, Maria José Nunes, tem capítulo sobre negros e mulatos na selva, Sérgio Ivan Gil Braga trabalha manifestações culturais, Jamily Souza, conta a história da festa de São Benedito, Sidney Barata apresenta experiências da cultura hip-hop. Ednailda Santos fala dos docentes negros na Ufam, enquanto em dupla Arlete Anchieta e Gláucio Gama tratam da presença de estudantes universitários negros.

Com relação a presença negra no Amazonas, temos ainda o seguinte:

Pesam sobre a região amazônica um sem número de visões equivocadas e distorcidas, tanto pela ótica popular externa quanto pela interna. Tais visões se aplicam inclusive em relação à composição étnicoracial das populações e respectivas influências demográfica, históricas, culturais e sociais, persistindo algumas premissas falaciosas sobre a região, que com variações apontam um mesmo eixo de pensamento: $A$ da quase exclusiva presença e ancestralidade indígena;

A da inexistência ou inexpressiva presença de população negra/afrodescendente;

A de que a população seria composta virtualmente apenas por indígenas, brancos ou da figura típica regional amazônica, o caboclo, que por critérios científicos/sociais, não configura na realidade grupo étnico-racial, mas sim uma identidade cultural regional;

A dispersão, a não consolidação/sistematização e divulgação das várias 
fontes e dados sobre a presença negra no Amazonas, tem resultado no processo já tradicional de negação e invisibilização de tal presença. Ao resgatar e ampliar os registros de personagens históricos afrodescendentes na região, bem como, seus reflexos sociais e no patrimônio material e imaterial, pretende-se ajudar a reverter a situação inicialmente aventada, para tal se fazem necessárias pesquisas e publicações típicas das linhas da História Social e Antropologia Social, e é justamente isso o que vem ocorrendo fortemente nos últimos anos. O primeiro ponto para desconstruir essa negação de presença é estatístico/demográfico e histórico. (SILVA JUNIOR, 2019, p. 224).

Tal consolidação/sistematização é importante para a valorização dos indivíduos desse grupo na sociedade em que se relacionam de forma integrada ou envolvida, com a consequente redução de preconceitos e discriminações.

Muito embora a região e o estado possuam na sua formação demográfica e cultural uma diversidade étnico-racial e cultural, sempre associada sobretudo ao elemento indígena, bem como a miscigenação com o branco, nenhuma das suas raízes é tão negada e ocultada quanto a do elemento negro, dai ser esse o foco do texto, uma vez que tal presença precisa ser afirmada.

Os estudos de presença negra têm esse condão, ao ajudar a desfazer um dos 4 sentimentos comuns no preconceito racial:

\begin{abstract}
São quatro os sentimentos que estarão sempre presentes no preconceito racial do grupo dominante: (a) de superioridade; (b) de que a raça subordinada é intrinsecamente diferente e alienígena; (c) de monopólio sobre certas vantagens e privilégios; e (d) de medo ou suspeita de que a raça subordinada deseje partilhar as prerrogativas da raça dominante. (BLUMER, 1939).
\end{abstract}

No caso, em especial o item (b), já que muito do preconceito e discriminação vem da percepção generalizada do grupo socialmente hegemônico, de que aquele grupo não faz parte tradicional da conformação daquela sociedade, que seriam intrusos, deslocados, mesmo tendo presença mais antiga ou contemporânea, o que combinado com o item (d) gera a noção que não lhes caberiam direitos ou posições maiores ou similares, causando o efeito dos "estrangeiros na própria terra" e situações conflituosas, como as vivenciadas por comunidades tradicionais, a exemplo das indígenas, quilombolas e outras.

\title{
3 POTENCIALIDADES E PESQUISAS TEMÁTICAS REALIZADAS NO ACERVO DO TJAM
}

O acervo do TJAM segundo o seu gerente Manoel Pedro Neto, é estimado 
entre 5 e 6 milhões de documentos entre processos judiciais e documentação administrativa, o número exato ainda não é possível definir, já que nem todos documentos passaram pelo cadastramento em sistema eletrônico de , e parte do acervo foi recebida em período anterior ao controle arquivístico profissional, sem contagem e registro disponíveis, o que está sendo feito paulatinamente, à medida que são cadastrados no sistema eletrônico. Os mais antigos datam de 1839:

No Arquivo Central do TJAM, o acesso do pesquisador se dá por formulário de solicitação oficiada ao Presidente do Poder, tal formulário contém os dados de qualificação, vinculação e contato do solicitante, o tema e recorte temporal da pesquisa. A solicitação passa por análise no setor de Arquivo que faz parecer informando a possibilidade de utilidade do acervo ou não, sendo posteriormente autorizado ou não o acesso. Os pesquisadores autorizados contam com acompanhamento e apoio de servidores do Arquivo e dos estagiários na área de história.

Parte do acervo histórico do TJAM já está registrado em instrumentos de pesquisa: Guia, Inventário e Catálogo. Disponibilizados online a partir do portal do TJAM (TRIBUNAL DE JUSTIÇA DO AMAZONAS, 2020), no site do arquivo, o que facilita algumas consultas prévias da existência de processos úteis, com exceções tais documentos ainda não se encontram digitalizados. 
Figura 2 - Pesquisadores no arquivo.

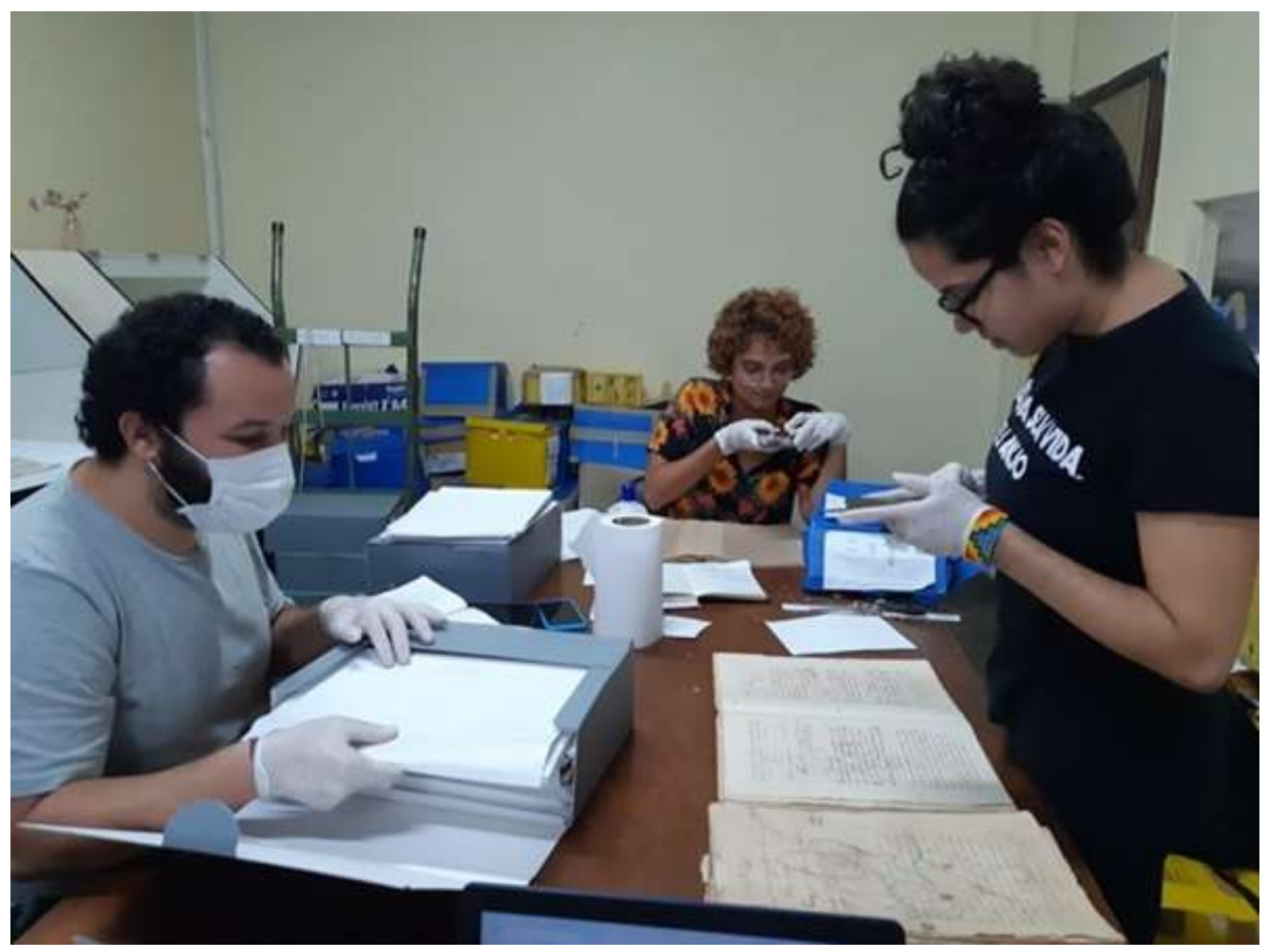

Fonte: Autor (2020).

\subsection{Pesquisas realizadas no acervo}

Desde o estabelecimento de um padrão de acesso dos pesquisadores ao acervo a partir de 2014, foram registrados 26 pesquisadores que se utilizaram do acervo em variadas temáticas. Entre os pesquisadores e pesquisadoras que acessaram o arquivo está Jessyka Samya Ladislau Pereira Costa:

A pesquisadora Jessyka Samya Ladislau Pereira Costa, que estuda na Universidade Estadual de Campinas, tem uma trajetória bem próxima ao Judiciário. "Em 2012, enquanto fazia graduação em História na Universidade Federal do Amazonas, fui estagiária no TJAM, o que foi uma experiência incrível para minha formação profissional devido ao contato com os processos judiciais e, também, pela troca de conhecimento com os funcionários do arquivo. Em 2014, iniciei o mestrado na Universidade Federal Fluminense pesquisando sobre a experiência no mundo do trabalho dos trabalhadores escravizados na cidade de Manaus entre 1850 a 1884. Os processos históricos do século XIX tinham acabado de ficar disponíveis para acesso e foi, então, quando iniciei minha pesquisa com esses documentos, que foram essenciais para o resultado final da minha dissertação", explica. Segundo Jessyka, desde a década de 1980 muitos historiadores começaram 
a demonstrar que o acesso aos processos judiciais como documento histórico, apesar de suas partes normativas, era um meio valioso para entender as complexas e dinâmicas relações sociais presentes em várias sociedades. "Seguindo essas dicas fui procurar se no acervo do TJAM existiam processos envolvendo pessoas escravizadas na cidade de Manaus. E existiam muitos! Eles me permitiram chegar mais próximo do cotidiano e da experiência de vida dessas pessoas durante esse período, possibilitando-me descrever partes do seu cotidiano de trabalho; das suas redes de sociabilidade; dos conflitos e lazeres que tinham na cidade de Manaus na segunda metade do XIX", conta. "Em 2017 iniciei o doutorado em História na Universidade Estadual de Campinas sob orientação do Prof. Dr. Ricardo Pirola. O objetivo da tese é analisar as formas de exploração de trabalho (livre, compulsório e escravo) a que foram submetidos escravos e indígenas na Província do Amazonas na segunda metade do século XIX. E os processos criminais têm sido de extrema importância para o percurso de escrita da tese, pois estão me permitindo debater sobre as redes de arregimentação compulsória de trabalhadores que existiam na região e que eram usadas principalmente nas áreas produtoras de borracha", explica a doutoranda e ex-estagiária demonstrando a importância do acervo histórico do TJAM. (TRIBUNAL DE JUSTIÇA DO ESTADO DO AMAZONAS, 2019, p. 3-4).

\subsection{Pesquisa temática de presença negra}

Das 26 pesquisas solicitadas e registradas, 5 foram direta ou grandemente relacionadas à temática de presença negra, aqui fazemos referência somente ao título provisório fornecido quando da solicitação, uma vez que é normal entre o pedido inicial de acesso para pesquisa e as defesas junto às instituições, não apenas a alteração do nome, como de abordagens e recortes. Algumas dessas pesquisas seguem da graduação ao doutorado com alterações a cada nível, e ainda estão em andamento, por tal é indicada a referência para o Curriculum Lattes dos pesquisadores caso se deseje verificar a qualquer tempo o estado atualizado resultante da pesquisa.

Jéssyka Sâmya Ladislau Pereira Costa (COSTA, 2020), atualmente doutoranda na Universidade Estadual de Campinas, pesquisou trabalhadores em meados do Séc. XIX, notadamente a população escravizada. Pedido de Pesquisa de 2015: "Atuação de Homens e Mulheres nos mundos do trabalho na Província e Estado do Amazonas 1850 - 1900".

Juarez Clementino da Silva Junior, no mestrado trabalhou personalidades negras dos poderes do Estado no Amazonas oitocententista. Pedido de Pesquisa de 2015: "Negros de Poder no Amazonas oitocentista"

Geisimara Soares Matos (MATOS, 2020), atualmente doutoranda na UFRJ Universidade Federal do Rio de Janeiro e que tem como principal tema o exGovernador do Amazonas em fins do Séc. XIX, Eduardo Ribeiro, primeiro governador 
afrodescendente do Brasil. Pedido de Pesquisa de 2015: "A Construção da Memória de Eduardo Gonçalves Ribeiro"

Laura Blanco (BLANCO, 2020), no mestrado tratou de Crimes praticados por escravos na Manaus oitocentista. Pedido de Pesquisa de 2017: "Vozes Negras: Criminalidade e Escravidão na Manaus Oitocentista".

Luiz Carlos de Matos Bonates (BONATES, 2020), é estudioso da Antropologia da Cultura afro-brasileira com ênfase na História da Capoeira e Cultura Popular no Amazonas. Pedido de Pesquisa de 2017: "Cultura Popular do Amazonas".

Os estudos de presença negra podem ser divididos em trabalhos sobre escravidão ou sobre emancipações e pós-abolição, uma tendência que vem crescendo bastante nos últimos anos. $O$ arquivo histórico do TJAM já avançado no período republicano também pode ser bem aproveitado nesse sentido, há por exemplo um processo em vias de disponibilização online, que trata de pendenga judicial entre um médico português e a ex-escravizada maranhense Dona Florinda Maria da Conceição, mãe do já citado Governador Eduardo Ribeiro.

O primeiro processo criminal do acervo amazonense que contém perícia com fotografias data de 1911, traz justamente um casal de não-brancos assassinado, Evaristo e Roza, citados como pardos, e de aparente origem indígena, sendo o acusado Antônio Ferreira de Souza, de então 24 anos, um óbvio negro. 
Figura 3 - Antônio Ferreira de Souza.

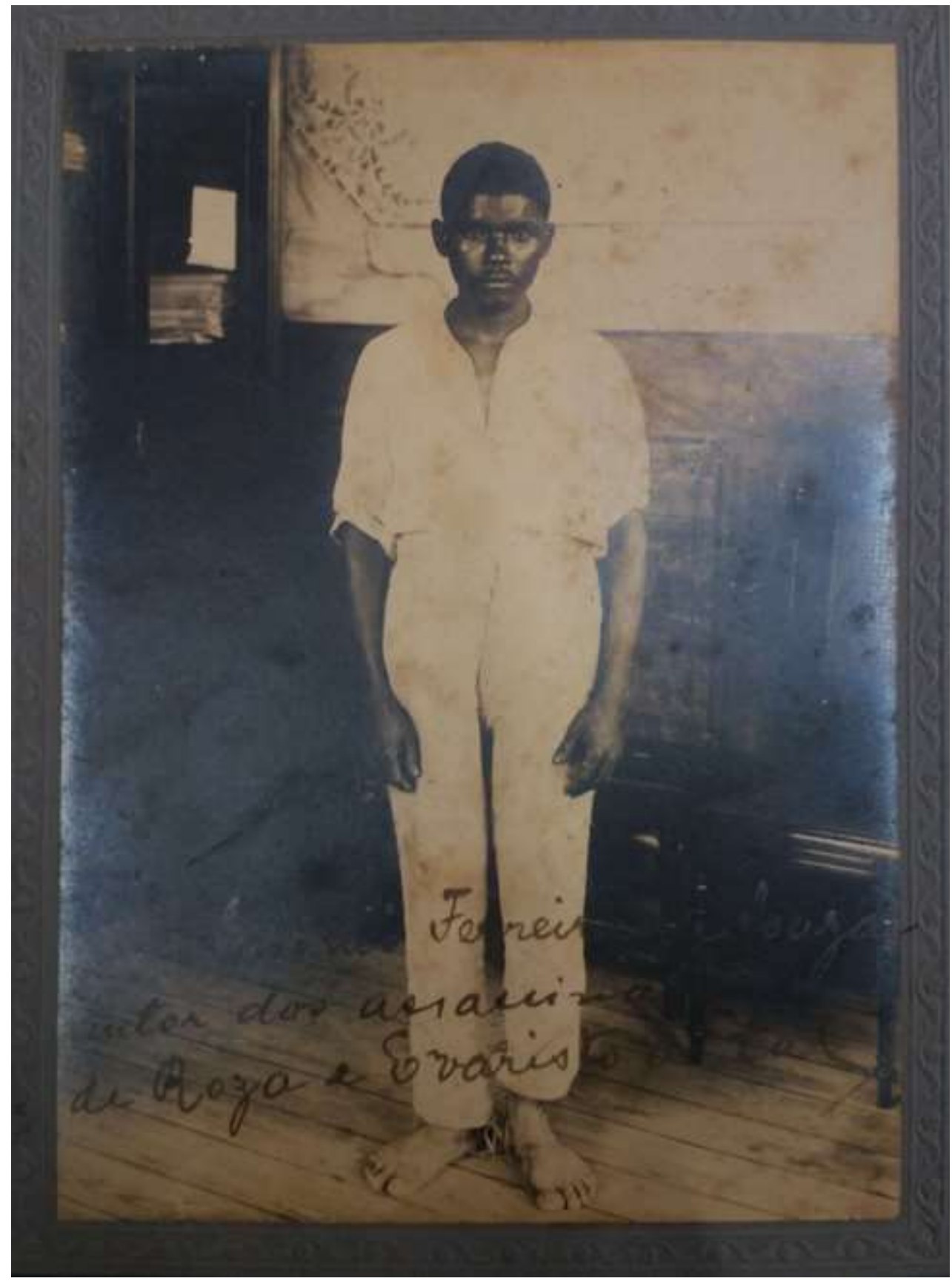

Fonte: Autor (2020), retirado do acervo histórico TJAM.

\section{3 "Africanos livres" e o selo Memórias do Mundo Brasil}

Ao contrário do que possa parecer em um primeiro momento, o termo "africanos livres" aqui utilizado não faz referência a africanos libertos pela ou na Justiça amazonense do século XIX, mas sim uma condição ou status aplicado aos resgatados do tráfico negreiro, já ilegal na segunda metade do século. A proposta da 
candidatura do TJAM ao MoW-Brasil 2018 explana tal importância para os estudos de presença negra e relações raciais:

\begin{abstract}
A história do pré-abolição da escravidão no Brasil segue sendo um campo de estudos de alto interesse, porém, a presença negra na Amazônia pré e pósabolição, foi até recentemente invisibilizada e minorada. Cabe observar que entre outros pontos históricos pouco conhecidos nacionalmente está a abolição no Amazonas, ocorrida em 1884, portanto, quatro anos antes da Lei Áurea. O tema presença negra na Amazônia ganhou nos últimos anos o interesse dos pesquisadores e o empenho em desconstruir a sua negação. Para tal é importante a divulgação, o acesso e conhecimento de documentos relacionados. Os chamados "africanos livres", aqueles especialmente identificados como traficados ilegalmente após a lei Eusébio de Queiroz, seguiam tutelados e prestando serviços obrigatórios ao Estado por 14 anos até sua emancipação, configuram parte importante da temática do préabolição. O Tribunal de Justiça do Estado do Amazonas, apresenta a candidatura de 4 processos judiciais selecionados de seu acervo, no recorte de 1.859 a 1.866 , envolvendo parte desses personagens em contexto mais personalizado e pouquíssimo conhecido que é o da região amazônica, podendo eles colaborarem significativamente para a pesquisa e reversão da já citada minoração da presença na região e historiografia nacional. (TRIBUNAL DE JUSTIÇA DO ESTADO DO AMAZONAS, 2018, p. 2-4).
\end{abstract}

O tema "africanos livres" e "africanos livres no Amazonas" constam de livros de Beatriz Mamigonian (2017) e de Patricia Melo Sampaio (2002).

Em tais processos, todos de júri, em que na época eram também julgados os crimes de ofensas físicas é possível vislumbrar uma situação rara, em que se pode acessar registros de depoimentos em primeira pessoa desses personagens, coisa incomum a pessoas das classes menos favorecidas, vislumbrar relações comunitárias, práticas sociais e como se davam sociabilidades em um contexto de "liberdade" convivente com um ainda ativo sistema escravista. Tais processos estão registrados em Guia, Inventário e Catálogo, com as descrições arquivísticas e respectivas digitalizações, de forma online a partir do portal do TJAM. 
Figura 4 - Conjunto documental "africanos livres" pré-restauro.

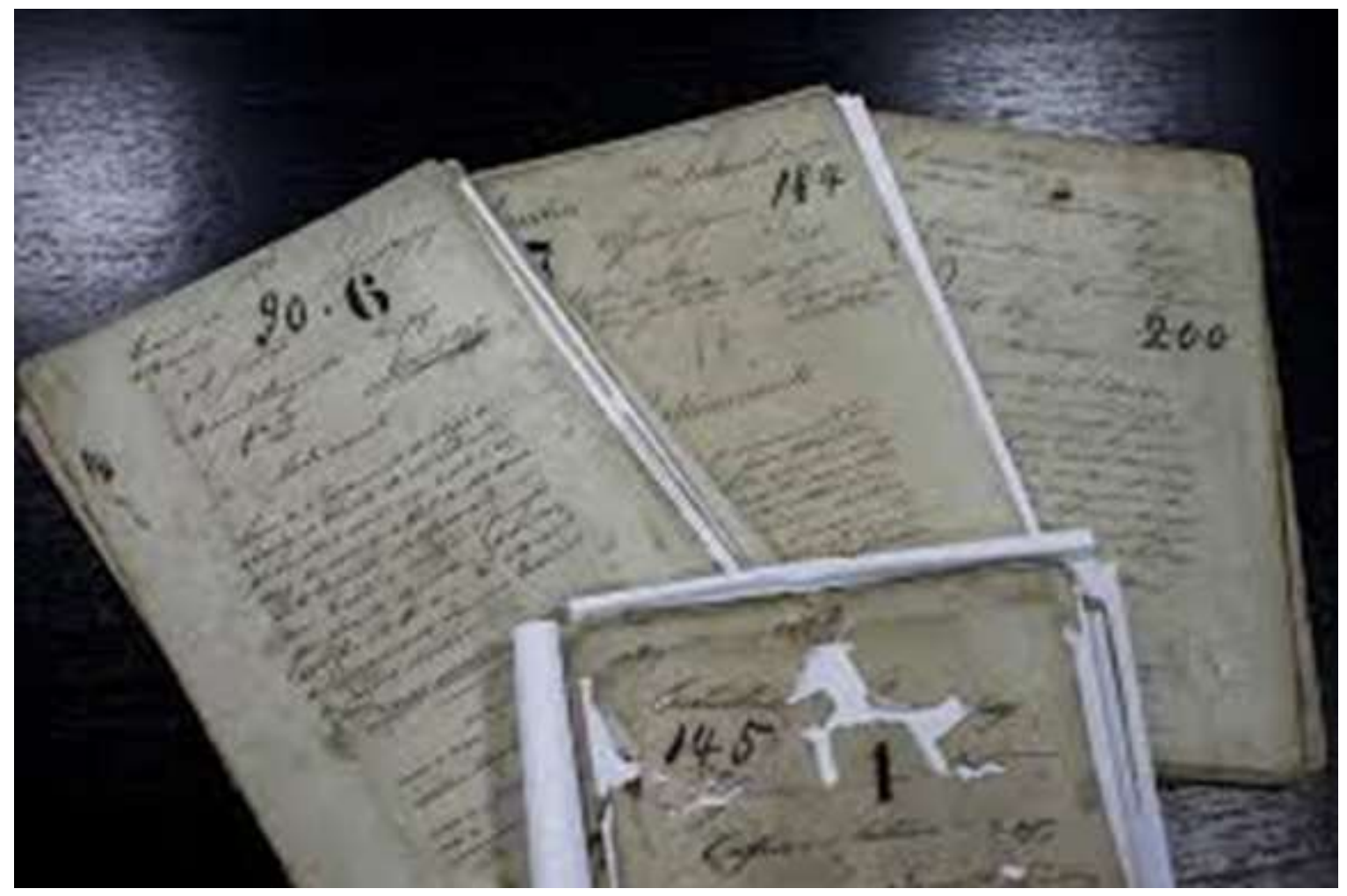

Fonte: Autor (2020).

O selo MoW Brasil deve ser exibido nas exposições e material gráfico relacionado ao acervo.

Figura 5 - Selo MoW 2018.

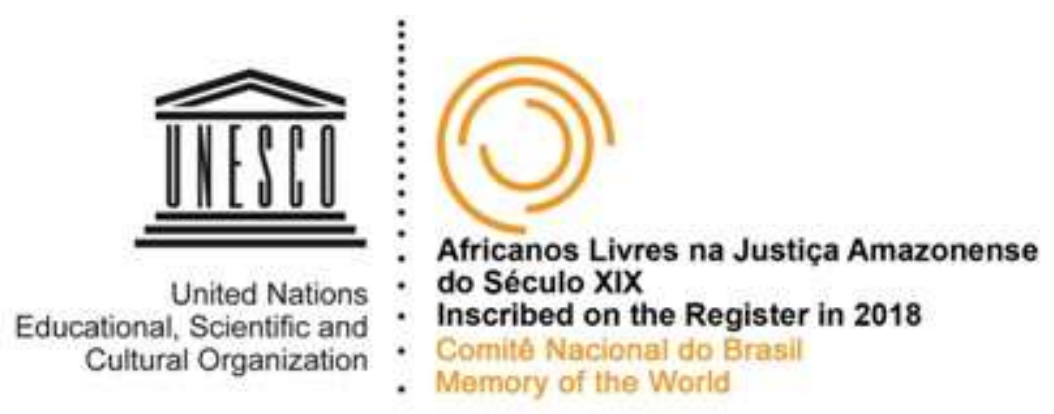

Fonte: Tribunal de Justiça do Amazonas (2020). 
Figura 6 - Premiação Mow Brasil.

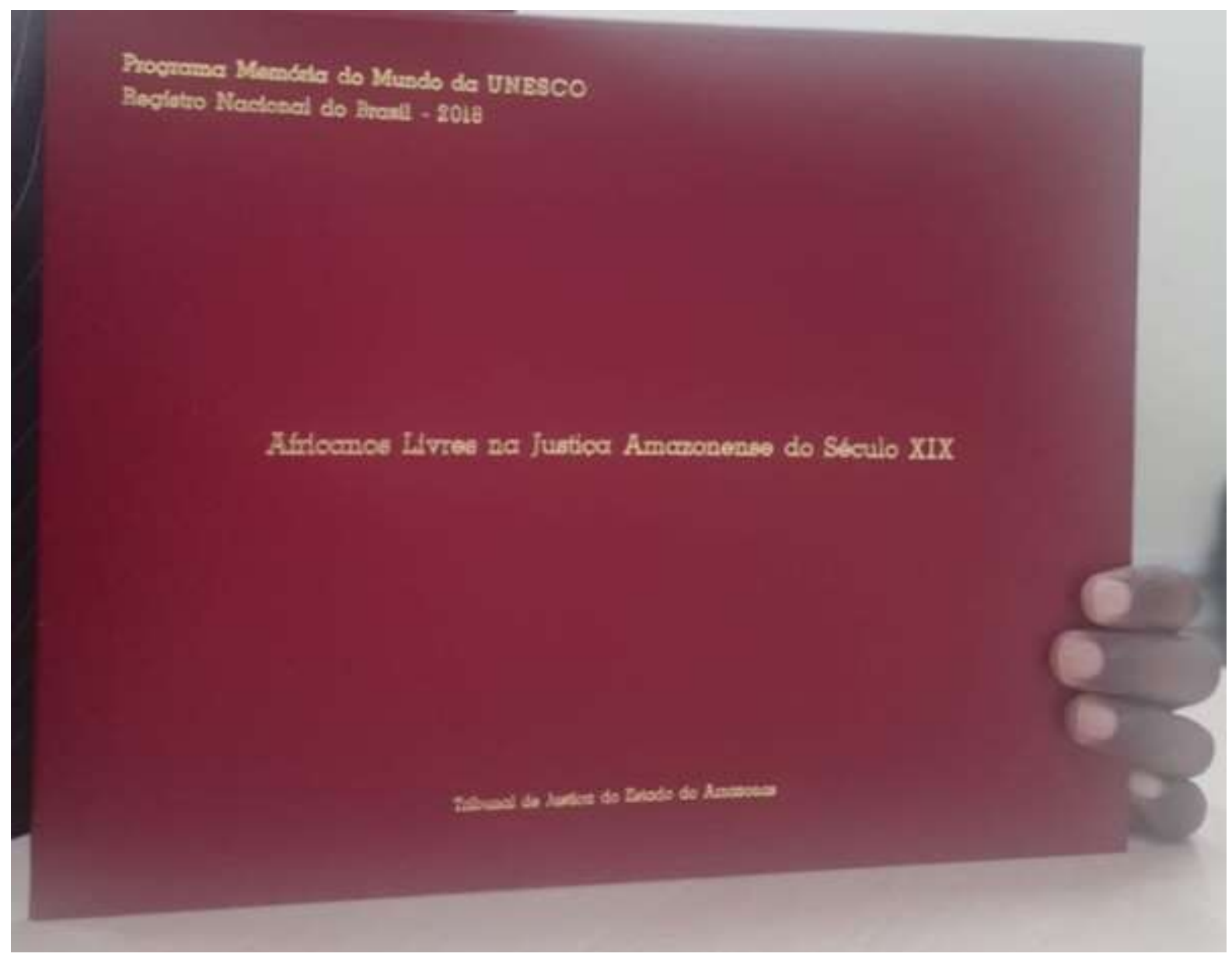

Fonte: Autor (2020).

A premiação teve grande repercussão na imprensa local. 
Figura 7 - Parte da repercussão na Imprensa.

\section{Processos centenários do TJAM sobre 'africanos livres' recebem selo 'Memória do Mundo', da Unesco}

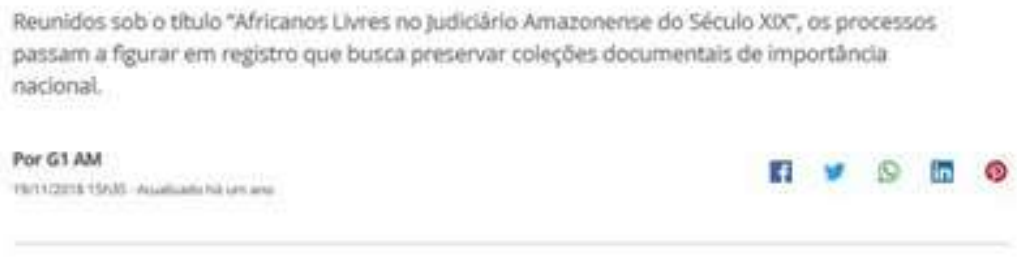

Fonte: Processos (2018).

\section{DOS RESULTADOS E CONSIDERAÇÕES FINAIS}

Diante do exposto e sendo o objetivo geral chamar a atenção para as possibilidades dos arquivos judiciais como fontes importantes para a pesquisa e afirmação de presença negra, e o específico apresentar como já foi e está sendo utilizado o acervo do TJAM em tal sentido. Dada a potencialidade do acervo, os resultados observáveis na experiência descrita indicam uma utilização futura promissora. A conquista da premiação MoW-Brasil 2018 não é o objeto desse texto, porém de forma acessória é importante, pois veio justamente a partir da opção pela temática de presença negra, em um contexto de desconstrução da negação da mesma. Também indica a relevância tanto da temática quanto da qualidade do acervo do TJAM para a mesma, além do compromisso do órgão para com o respeito à diversidade local.

\section{REFERÊNCIAS}

BLANCO, Laura Stella Passador de Luiz. Crimes praticados por escravos na Manaus oitocentista. 2020. Dissertação (Mestrado em História) - Instituto de Filosofia, Ciências Humanas e Sociais, Universidade Federal do Amazonas, Amazonas, 2020. 
BLUMER, H. The nature of racial prejudice. Social Process in Hawaii, Honolulu, v. 5, p. 11-20, 1939.

BONATES, Luiz Carlos de Matos. Currículo do sistema currículo Lattes. [Brasília]: CNPq, 2020. Disponível em: http://lattes.cnpq.br/0643251828351181. Acesso em: 30 jul. 2020.

COSTA, Jéssyka Sâmya Ladislau Pereira. Currículo do sistema currículo Lattes. [Brasília, DF]: CNPq, 2020. Disponível em: http://lattes.cnpq.br/9300293060966083. Acesso em: 30 jul. 2020.

CUNHA JUNIOR, Henrique. A formação de pesquisadores negros. Com Ciência Revista Eletrônica de Jornalismo Científico, [S. I.], 2003. Disponível em: http://www.comciencia.br/dossies-1-72/reportagens/negros/17.shtml. Acesso em: 22 ago. 2020.

GOMES, Nilma Lino. Intelectuais negros e produção do conhecimento: algumas reflexões sobre a realidade brasileira. In: SANTOS, Boaventura de Sousa;

MENESES, Maria Paula (org.). Epistemologias do Sul. São Paulo: Cortez, 2010. p. 492-516.

$\mathrm{KICH}$, Tassiara Jaqueline Fanck. O poder judiciário e as fontes para a história da sociedade. In: ENCONTRO ESTADUAL DE HISTÓRIA, 10., 2010, Santa Maria. Anais [...]. Santa Maria: UFSM: UNIFRA, 2010. p. 1-15. Disponível em: http://www.eeh2010.anpuh-

rs.org.br/resources/anais/9/1277774267_ARQUIVO_TrabalhocompletoTassiaraKich ANPHU.pdf. Acesso em: 22 ago. 2020.

MAMIGONIAN, Beatriz Gallotti. Africanos livres: a abolição do tráfico de escravos no Brasil. São Paulo: Companhia das Letras, 2017.

PROCESSOS centenários do TJAM sobre 'africanos livres' recebem selo 'Memória do Mundo', da Unesco: reunidos sob o título "Africanos Livres no Judiciário Amazonense do Século XIX", os processos passam a figurar em registro que busca preservar coleções documentais de importância nacional. G1 AM, [S. I.], 2018.

Disponível em: https://g1.globo.com/am/amazonas/noticia/2018/11/19/processoscentenarios-do-tjam-sobre-africanos-livres-recebem-selo-memoria-do-mundo-daunesco.ghtml. Acesso em: 31 jul. 2020.

PROENÇA FILHO, Domício. A trajetória do negro na literatura brasileira. Estudos Avançados, São Paulo, v. 18, n. 50, p. 161-193, 2004. Disponível em:

http://www.scielo.br/scielo.php?script=sci_arttext\&pid=S0103-

40142004000100017\&lng=en\&nrm=iso. Acesso em: 20 ago. 2020.

SAMPAIO, Patrícia M. Nas teias da fortuna: acumulação mercantil e escravidão em Manaus, século XIX. Mneme - Revista Humanidades, [S. I.], v. 3, n. 6, p. 49-70, 2002. 
SAMPAIO, Patricia Melo. 0 fim do silêncio: presença negra na Amazônia. Belém: Açaí: CNPq, 2011.

SANTOS, Boaventura de Sousa. A gramática do tempo: para uma nova cultura política. São Paulo: Cortez, 2006.

SILVA, Antonio Ozaĺ da. A representação do negro na política brasileira. Espaço Acadêmico, [S. I.], v. 4, n. 40, p.1-1, 2004. Mensal. Disponível em: http://www.espacoacademico.com.br/040/40pol.htm. Acesso em: 20 ago. 2020.

SILVA JUNIOR, Juarez Clementino da. PRESENÇA NEGRA NA AMAZÔNIA: o uso de biografias. In: SILVA, Júlio Claudio da; ROCHA, João Marinho da; SANTOS, Joceneide Cunha dos. Ensino de história e cultura afro-brasileira: desafios e perspectivas na Amazônia. Manaus: Editora Uea, 2019. p. 62-73. Disponível em: http://repositorioinstitucional.uea.edu.br/handle/riuea/1611. Acesso em: 23 ago. 2020.

SILVA JUNIOR, Juarez Clementino da. Afroamazonenses: a desconstrução de uma presença negada. In: SILVA, Gimima; PUGA, Lúcia; RODRIGUES, Izaura (org.). ENCONTRO DE PERSPECTIVAS: ALFABETIZAÇÃO POLÍTICA, RELAÇŌES DE PODER E CIDADANIA, 4., 2019, Rio de Janeiro. Anais [...]. Rio de Janeiro: Letra Capital, 2019. p. 223-228. Disponível em:

http://www.pos.uea.edu.br/data/area/download/download/107-1.pdf. Acesso em: 23 ago. 2020.

TRIBUNAL DE JUSTIÇA DO AMAZONAS. Principal. Portal do Arquivo Judiciário, Amazonas, 2020. Disponível em:

http://www2.tjam.jus.br/arquivo/index.php/principal.html. Acesso em: 30 jul. 2020.

TRIBUNAL DE JUSTIÇA DO ESTADO DO AMAZONAS. Arquivo Central do TJAM é fonte de informações históricas para pesquisadores: situações narradas em processos seculares do acervo do Tribunal subsidiam dissertações de mestrado e teses de doutorado, entre outros trabalhos acadêmicos. Tribunal de Justiça do Estado do Amazonas, Amazonas, 2019. Disponível em: https://www.tjam.jus.br/index.php/menu/sala-de-imprensa/1763-arquivo-central-dotjam-e-fonte-de-informacoes-historicas-para-pesquisadores. Acesso em: 30 jul. 2020.

TRIBUNAL DE JUSTIÇA DO ESTADO DO AMAZONAS. Processos centenários do TJAM envolvendo "africanos livres" vão receber o selo "Memória do Mundo", da Unesco Reunidos sob o título "Africanos Livres no Judiciário Amazonense do Século XIX", os processos passam a figurar em registro que busca preservar coleções documentais de importância nacional. Tribunal de Justiça do Estado do Amazonas, Amazonas, 2018. Disponível em: https://www.tjam.jus.br/index.php/menu/sala-de-imprensa/659-processoscentenarios-do-tjam-envolvendo-africanos-livres-vao-receber-o-selo-memoria-domundo-da-unesco. Acesso em: 30 jul. 2020. 